ON THE RECORD

\section{(CWe are seeking a jury of twelve - the most qualified and the most cynical."}

Engineers at Irish company Steorn are so convinced that they have developed a source of freeenergy, they are challenging scientists worldwide to prove them wrong.

'They're pretty small. Maybe we can bring in a ping-pong ball."

Geza Gyuk on adding new planets to Chicago's Adler Planetarium.

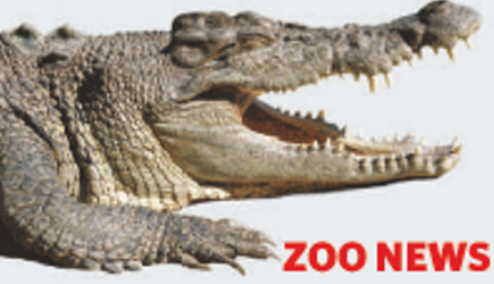

Snapdecision

As astronomers discuss the

definition of planets, the

Australian governmenthas been

considering what creatures to

describeas fish. In a law meant

to aid regulation of aquatic

commerce, passed on 17 August, some were surprised to see

that crocodiles made the grade,

alongside prawns and scallops.

Preposterous piglets

Officials at the Copenhagen Zooin

Denmark were stunnedlast week when they discovered five piglets in the den of a babirusa, a wild hog native to Indonesia. The newborns apparently resulted from the animal's tryst witha domestic pig who kept it company in its cage. Zoologists say the two species are only remotely related, and the mating is equivalent to a cow and a goat producing offspring.

\section{NUMBER CRUNCH}

The ozone hole is recovering but not very quickly...

29 million $\mathrm{km}^{2}$ was the maximum size of the Antarctic ozone hole in 2000 - the biggest ever.

27 million $\mathbf{k m}^{2}$ was the maximum size of the ozone hole five years later.

59 years is how long it should take for the hole to close.

\title{
Early embryos can yield stem cells... and survive
}

A single cell can be teased from a human embryo and used to produce stem cells while leaving the embryo intact. The process, published online in Nature this week, could enable stem-cell lines to be generated without the controversial destruction of human embryos - but some ethical objections remain.

Embryonic stem cells, prized for their ability to make other tissue types, are typically extracted from an embryo that has developed into a hollow ball called a blastocyst. The process pulls the embryo apart and destroys it.

This week's paper shows that stem-cell lines can be grown from less developed embryos - balls of eight to ten cells - and the process could leave them unscarred (I. Klimanskaya et al. Nature doi:10.1038/nature05142; 2006).

The technique is similar to that used for preimplantation genetic diagnosis, an option during in vitro fertilization (IVF) in which a single cell is extracted from an embryo and tested for genetic disorders. Last year, a team led by Robert Lanza of Advanced Cell Technology in Worcester, Massachusetts, showed that single cells extracted from mouse embryos in this way could be grown into stem-cell lines (Y. Chung et al. Nature 439, 216-219; 2006).

Since then the team has taken cells from 16 spare IVF human embryos, and put them into culture. From a total of 91 cells, the researchers grew two embryonic stem-cell lines that have survived for eight months so far and are able to form different types of tissue. In the experiment, the embryos were dismantled cell by cell; but other embryos should survive the extraction of a single cell, just as they do in preimplantation genetic diagnosis. Lanza says that the researchers should be able to achieve a higher success rate for cell lines by adjusting the cell culture conditions. Several other groups have been trying similar approaches, but with no reported success so far.

"It shows it's possible to make any number of lines in future without harming embryos or impairing their development," says bioethicist Ronald Green, head of Dartmouth College Ethics Institute in Hanover, New Hampshire, and an ethics adviser to Lanza's company. "I think it's a way out of the moral impasse in the United States." President George W. Bush has limited federally funded research on human embryonic stem cells to lines derived before August 2001, on the grounds that he is opposed to destroying embryos to create more lines.

Still, the technique is unlikely to answer all ethical concerns (see Nature 437, 1076-1077; 2005). There are fears that removing a cell from an embryo will lower its chances of implantation in the womb, or alter its development and cause later health problems for the resulting child. Lanza answers this by saying that the risks of the procedure are minimal and that it would only be performed on embryos that are to undergo preimplantation genetic diagnosis anyway. Others object that the removed cell itself may have the potential to develop into an entire new embryo, and that this is being destroyed.

The method joins a raft of other techniques that have been proposed for deriving ethically sound human embryonic stem cells, such as using embryos that have been genetically altered so that they cannot develop into babies. "None of those methods was likely to satisfy all the critics, and I don't think this one will either," says Tom Murray, president of the Hastings Center, a bioethics research institute in Garrison, New York.

Helen Pearson

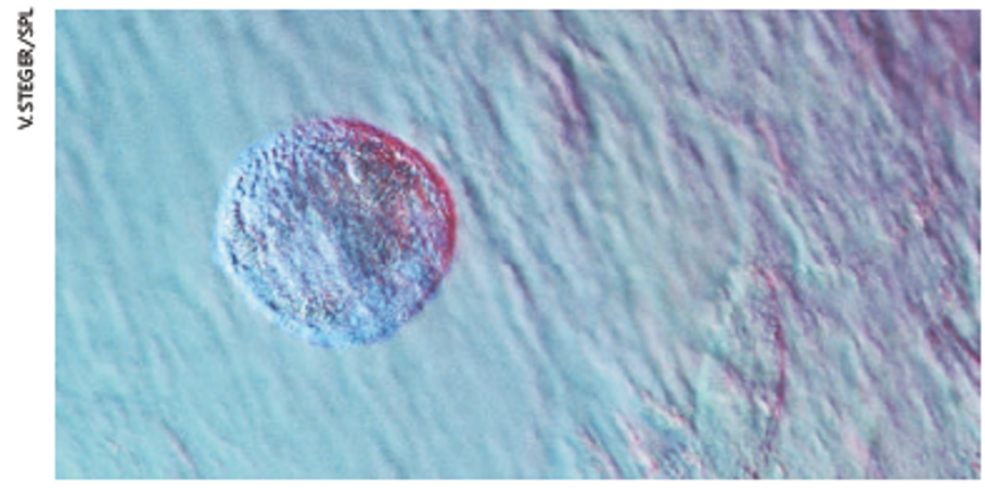

Human embryonic stem cells can develop to form any kind of tissue, and could be used to treat fatal diseases. 